\title{
Infarction of Hürthle Cell Tumor of Thyroid Following Fine Needle Aspiration
}

\author{
Vikranth Varma, Sushma Chelmeda \\ Department of Pathology, American Oncology Institute, Hyderabad-500019, India.
}

\begin{abstract}
Corresponding Author:
Dr. Vikranth Varma

Email: vikranth88afmc@gmail.com

This is an Open Access article distributed under the terms of the Creative Commons Attribution License (creativecommons.org/ licenses/by/3.0).
\end{abstract}

Received Accepted

Published

August 10, 2017

September 13, 2017

October 15,2017

\begin{abstract}
Background: Fine needle aspiration is widely recognized as an important test in the evaluation of thyroid nodules. Complications of the procedure are uncommon with partial or incomplete infarction of the thyroid neoplasm being rare. Amongst the thyroid neoplasm, Hurtle cell neoplasms are more prone to such infarctions. Case Report: We report a case of Hurthle cell neoplasm which had undergone an infarction post fine needle aspiration. Conclusion: An infarcted nodule in thyroidectomy specimen should induce the histopathologist to look carefully for detailed morphologic features.
\end{abstract}

Keywords: Adenoma, Biopsy, Infarction, Thyroid Neoplasms, Thyroid Nodule, Thyroidectomy.

\section{Introduction}

In case of difficulty in the interpretation of fine needle aspiration (FNA) smears of a thyroid nodule, histopathologic examination is advised to arrive at a definitive diagnosis. On rare occasions, a specific diagnosis may be given based on cytologic examination, but FNA is followed by infarction of the thyroid nodule, with resultant difficulty in interpretation or even mis-interpretation of histopathologic material. We hereby report one such case.

\section{Case Report}

A 63 year old male presented to the cytology department with a solitary nodule in the left lobe of the thyroid [Fig.1a]. He was clinically and biochemically euthyroid. FNA was cellular with Hürthle cells arranged in syncitial clusters, sheets and forming micro-follicles. Colloid was seen focally [Fig.1b,c]. FNA diagnosis was rendered as suggestive of a hyperplastic Hürthle cell nodule in a nodular goiter; however, the possibility of Hürthle cell neoplasm could not be excluded. A histopathology examination was advised. Left hemi-thyroidectomy was done 4 weeks after the FNA. Cut section revealed a nodule yellow-white in color with a thick capsule [Fig.1d]. Histopathology showed complete infarction of the nodule with some granulation tissue and histiocytes at the periphery [Fig.2a]. A thin rim of viable tumor composed of Hürthle cells forming micro-follicles was seen focally in the sub-capsular zone. No capsular or vascular invasion was seen [Fig.2b].

\section{Discussion}

Fine-needle aspiration biopsy is a simple diagnostic tool in evaluation of thyroid nodules. High diagnostic accuracy and a very low incidence of minor or major complications are reasons responsible for the immense popularity of this diagnostic technique. Tissue damage resulting from the use of fine-needles is a rare occurrence, unlike large needle biopsy where hemorrhagic necrosis and granulation tissue is often noted along the needle track [Fig.2a] in the surgically excised specimen. However, several morphologic alterations following FNA biopsy have been reported in the recent literature [2-11]. KeyhaniRofagha et al. [2] and Layfield and Jones [3] 


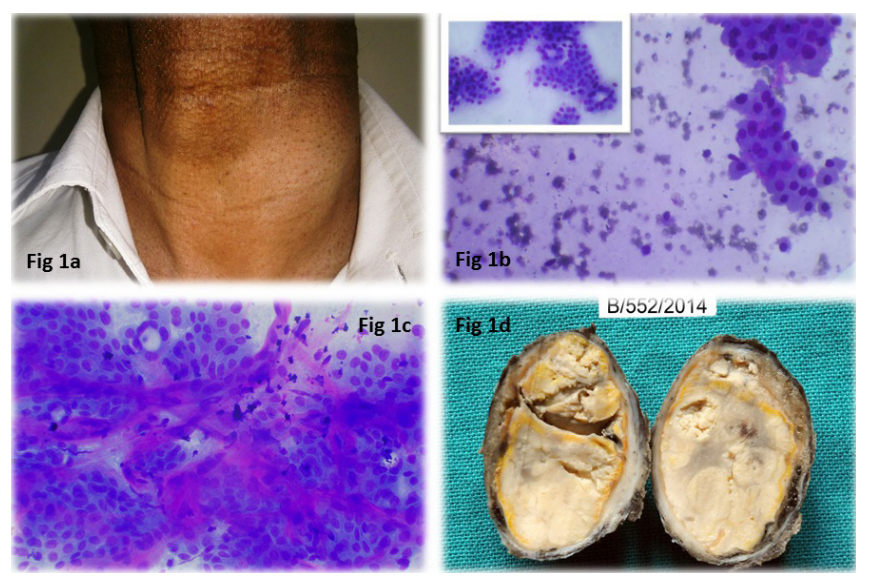

Fig.1(a): Clinical photograph depicting solitary nodule in left lobe of thyroid. (b): Hürthle cells in sheets and forming microfollicles against colloid (MGG, x400). (c): Hürthle cells in syncytial clusters with traversing capillaries (MGG, x400). (d): Cut section of the nodule with thick capsule. C/S: Yellow-white in color.

reported the subtotal necrosis of two Hurthle cell tumors subsequent to FNA. Comparable to our case, histopathological examination of the surgical specimens revealed only viable tumor cells in a small and inapparent rim at the periphery, which could have been overlooked. LiVolsi and Merino [4] compiled an impressive list of post-fine-needle biopsy changes dubbed as worrisome histologic alterations following fine-needle aspiration of thyroid (WHAFFT). In a review of 3,000 thyroidectomies, they observed a spectrum of changes in 300 cases, an incidence of $10 \%$. These authors grouped changes in two categories, acute and chronic. The acute changes were observed within 3 weeks of fine-needle biopsy and included hemorrhage, granulation tissue, giant cells, siderophage, mitosis, necrosis, nuclear clearing, poorly defined granuloma, capsular distortion, and rarely, infarction. The chronic changes were characterized by linear fibrosis near siderophages, oncocytic metaplasia, spindle cell, and squamous type, infarction, pseudo-invasion of the capsule, significant nuclear atypia, cyst formation, papillary degeneration, and calcification.

The current case perhaps represents the end stage of the infarcted neoplasm. All the above

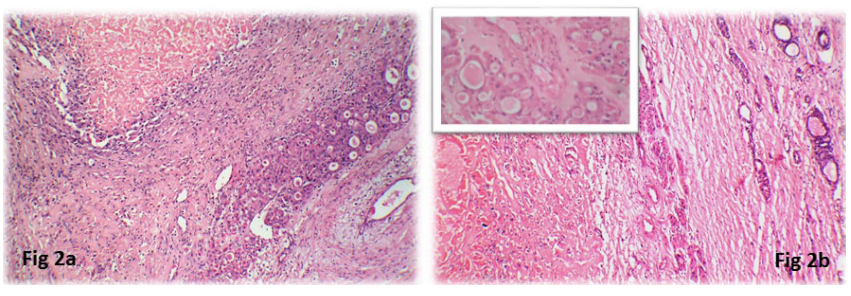

Fig.2(a): Needle tract with granulation tissue and infarcted tumor ( $H \& E, x 40)$. (b): Viable subcapsular tumor cells. Zone of granulation tissue and infarcted tumor to the center of the nodule ( $H \& E$, x200).

mentioned changes do occur spontaneously, especially in adenomatous goiter and occasionally in a neoplasm. FNA biopsy specimens in such instances will exhibit necrosis, degenerating cells, giant cells, and siderophages. Hurthle cell neoplasms were found to be more prone for infarctions. 53\% cases in our series were Hurthle cell tumors. We had encountered one Hurthle cell tumor which showed infarcted neoplasm within 4 weeks. The exact incidence of infarction is difficult to determine as number of thyroidectomies performed in patients who had fine-needle biopsy procedures was not known. Out of 22 cases with thyroid nodule infarction subsequent to FNA reported by Kini et al [5], 15 were cytologically and histologically oxyphilic tumors, whereas five were papillary carcinomas and two follicular carcinomas. Furthermore, this phenomenon is not restricted to the thyroid gland, since Kern [6] described the necrosis of an oncocytic Warthin tumor of the parotid gland subsequent to FNA. Upto now, no relationship between post-FNA necrosis of thyroid nodules and the tumor size, the age or sex of the patient and previous or current therapy has been established. According to the literature, it seems likely that oncocytic tumors are particularly susceptible to post-FNA necrosis. Gordon et al. [7] reported an overall incidence of $9.8 \%$, very high compared to ours. The mechanism of infarction and its high incidence in Hurthle cell neoplasms is not known. Perhaps the increased vascularity makes the Hurthle cell neoplasm more susceptible to infarction. Reasons offered [7-9] included interruption of microvascular supply, 
compromised vascular supply from the extraction of large amounts of tissue, traumatic venous thrombosis, rough needle use, and multiple passes with rigorous aspiration. Post-FNA infarcted thyroid nodules may show all types of neoplasms. In a study of 28 neoplasms undergoing post-FNA infarction, the most common lesion was Hürthle cell tumors (15 cases), followed by PTCs ( 8 cases) and follicular neoplasms (5 cases) [9]. The importance of these changes lies in the fact that extensive necrosis and infarction will obscure the true nature of the neoplasm, and the cytologic diagnosis may not be confirmed histologically. Widespread necrosis in a neoplasm should alert the surgical pathologist to evaluate the specimen more carefully. It is imperative that the surgical pathologist be provided with the information on prior fine-needle biopsy procedure and the cytologic diagnosis. The diagnostic accuracy of papillary carcinoma, Hurthle cell tumors, and follicular neoplasm is quite high [8-10]. An unequivocal cytologic diagnosis of a neoplasm should not be taken lightly in the presence of hemorrhage and necrosis.

\section{Conclusion}

This case report indicates that an infarcted nodule in paraffin sections of a thyroidectomy specimen should induce the histopathologist to look carefully at the periphery of the nodule for surviving cells, if any, and their detailed morphologic features, especially if there is a prior FNA cytology report of any neoplasm.

Contributors: VV: literature search, histopathology; SC: manuscript editing, literature search, histopathology. VV will act as guarantor. Both authors approved the final version of the manuscript.

Funding: None; Competing interests: None stated.

\section{References}

1. Gelderblom AJ, vd Hoek W, Lips PT, Risse EK, Meijer CJ. A study of the importance of fine needle aspiration cytology in the diagnosis of solitary thyroid nodules. Neth J Med. 1990;36:13-18.

2. Keyhani-Rofagha S, Kooner DS, Keyhani M, O'Toole RV. Necrosis of a Hurthle cell tumor of the thyroid following fine needle aspiration. Case report and literature review. Acta Cytol. 1990;34:805-808.

3. Layfield LJ, Lones MA. Necrosis in thyroid nodules after fine needle aspiration biopsy: Report of two cases. Acta Cytol. 1991;35:427-430.

4. LiVolsi VA, Merino MJ. Worrisome histologic alterations following fine-needle aspiration of the thyroid (WHAFFT), Pathol. Annu. 1994;29:99-120.

5. Kini SR, Miller JM, Abrash MP, Gaba A, Johnson T. Post fine needle aspiration biopsy infarction in thyroid nodules. Mod Pathol. 1988;1:48A.

6. Kern SB. Necrosis of a Warthin's tumor following fine needle aspiration. Acta Cytol. 1988;32:207-208.

7. Gordon DL, Gattuso P, Castelli M, Bayer W, Emanuele MA, Brooks MH. Effect of fine needle aspiration biopsy on the histology of thyroid neoplasms. Acta Cytol. 1993;37:651-654.

8. Jayaram G, Aggarwal S. Infarction of thyroid nodule: A rare complication following fine needle aspiration. Acta Cytol. 1989;33:940-941.

9. Kini SR. Post-fine-needle biopsy infarction of thyroid neoplasms: a review of 28 cases. Diagn Cytopathol. 1996; 15:211-220.

10. Pandit AA, Vaideeswar P, Mohite JD. Infarction of a thyroid nodule after fine needle aspiration biopsy. Acta Cytol. 1998;42:1307-1309.

11. Das DK, Janardan C, Pathan SK, George SS, Sheikh ZA. Infarction in a thyroid nodule after fine needle aspiration: report of 2 cases with a discussion of the cause of pitfalls in the histopathologic diagnosis of papillary thyroid carcinoma. Acta Cytol. 2009;53:571-575. 